\title{
Effect of UV-C Light Treatment on Physicochemical and Bioactive Compounds in Apple and Pineapple Juices
}

\author{
C. Krishna Teja ${ }^{1 *}$, Shivashankar Sanganamoni ${ }^{1}$, B. Prabhakar ${ }^{2}$ and \\ Pavuluri Srinivasa Rao ${ }^{1}$
}

${ }^{1}$ Agricultural and Food Engineering Department, IIT Kharagpur, W.B - 721 302, India

${ }^{2}$ College of Food Technology, VNMKV, Parabhani, Maharashtra - 431 401, India

*Corresponding author

\begin{tabular}{|c|c|}
\hline & A B S T R A C T \\
\hline & \multirow{6}{*}{$\begin{array}{l}\text { The effect of ultraviolet (UV-C) on physicochemical (viz. } \mathrm{pH} \text {, total soluble solids } \\
\text { (TSS), Absorbance, total color difference), bioactive component (viz. ascorbic } \\
\text { acid, total phenolic content, antioxidant activity) of apple and pineapple were } \\
\text { studied during this research work. The process conditions for ultraviolet treatment } \\
\text { were treatment time }(5,10,15 \mathrm{~min} \text { ) and distance of sample from lamp source ( } 8.6 \text {, } \\
13.7,18.6 \text { and } 22.8 \mathrm{~cm} \text { ) at } 1 \mathrm{~mm} \text { sample thickness. The results obtained from this } \\
\text { study showed that the ultraviolet treatment (UV) doesn't have any significant } \\
\text { effect on pH, TSS of apple and pineapple juices. However, the UV treatment } \\
\text { conditions had significant effect on vitamin-C content. The color parameters (viz. } \\
\mathrm{L}^{*}, \mathrm{a}^{*} \text { and } \mathrm{b}^{*} \text { ) were slightly affected by ultraviolet treatment. The bioactive } \\
\text { components of apple and pineapple juices were affected by the treatment } \\
\text { conditions. The Antioxidant activity of both the juices showed a decreasing trend } \\
\text { with respect to an increase in dosage level. The obtained results suggested that, } \\
\text { ultraviolet treatment conditions slightly affect the quality parameters of apple and } \\
\text { pineapple juices. However, the changes were found to be minimum as that of } \\
\text { thermal treatments in literature. }\end{array}$} \\
\hline & \\
\hline $\begin{array}{l}\text { Ultraviolet } \\
\text { treatment, Apple } \\
\text { juice, Pineapple } \\
\text { Juice, pH, TSS, } \\
\text { Vit-C. }\end{array}$ & \\
\hline Article Info & \\
\hline $\begin{array}{l}\text { Accepted: } \\
26 \text { May } 2017 \\
\text { Available Online: } \\
\text { 10 June } 2017\end{array}$ & \\
\hline & \\
\hline
\end{tabular}

\section{Introduction}

Fruit juices are good sources of vitamins and minerals and are associated with many health benefits. The major component of the fruit juice is water. The other most common constituent is carbohydrates which comprise sucrose, fructose, glucose and sorbitol. Also, limited amount of protein and minerals are found in fruit juices. However fruit juice contains no fat or cholesterol. It was believed that fruit juices are safe from contamination due to their acidity however fruit juices can support the growth of several types of microorganisms, such as bacteria, yeasts and molds that are primarily responsible for causing the spoilage of these products.

The contamination and growth of pathogenic bacteria such as Escherichia coli (E. coli) O157:H7 in acidic food products, fruit juices and fruit-based drinks has caused great concern. Several outbreaks of illness caused by the consumption of fruits or fruit juices 
contaminated with Salmonella, E. coli O157:H7 and Cryptosporidium have been reported throughout the world.

Conventional thermal pasteurization is the most common technique employed for pasteurization of fruit juices. It is the best known technique in order to reduce the number of pathogenic organisms like E. coli O157:H7, Cryptosporidium parvum in various types of juices (Tandon et al., 2003). The thermal pasteurization of apple juice and pineapple juice involves $80-82^{\circ} \mathrm{C}$ for $2-3$ seconds and $90-95{ }^{\circ} \mathrm{C}$ for $15-30 \mathrm{~s}$ respectively.

Pasteurization is an effective technology in order to reach safety requirements. However, it has many limitations like cost of the equipment is prohibitive especially for small operations, adverse effects of thermal pasteurization on the food quality and increased demand for the fresh-like juice products.

Alternative methods are addition of micro biocidal agents, high pressure application, pulsed electric field, irradiation, and aseptic packaging.

However there are some disadvantages of these techniques. Opstal et al., (2006) reported the loss of ascorbic acid in the peroxidase applied fruit juices.

In another study it was shown that PEF treatment causes brightness in the color of orange juice (Min et al., 2003) and its application to industry is limited due to its high cost. Also, as light browning in the color of white grape juice was observed after the high pressure treatment (Daoudi et al., 2002). Considering these limitations of other techniques, UV-C radiation can be used as an alternative to other preservation techniques. This process does not produce chemical residues (Canitez, 2002). Besides, it is a low- cost operation and effective against many microorganisms (Bintsis et al., 2000). UVlight is the part of electromagnetic spectrum with wavelengths ranging from100-400nm. UV-light is traditionally subdivided into the following categories: UV-A range from315$400 \mathrm{~nm}$ and this range is responsible for Changes in human skin.

UV-B range from 280 to $315 \mathrm{~nm}$ and can cause skin burning and has the potential to cause skin cancer.

UV-C ranges from 200 to $280 \mathrm{~nm}$ and is very well known for its antimicrobial effect. It used for the decontamination of medical equipment, water treatments, drinking water, water for swimming pools, and surface disinfection of different fruits and other processing equipment. Application of UV light on various liquid foods like apple cider, orange juice, grape juice, milk and honey have been developed recently.

UV-C radiation germicidal properties are due to the DNA absorption of the UV-light which causes crosslinking between the neighboring pyrimidine nucleoside bases (thymine and cytosine) in the same DNA strand (Miller et al., 1999).

Due to this, the DNA transcription and replication is blocked, which compromises cellular functions and leads to cell death (Miller et al., 1999).

Application of UV light in liquid food products has shown positive results. Different modes of UV treatments can be applied to food products such as continuous mode, pulsed mode.

The present experiment was aimed to study the effect of ultraviolet treatment on physicochemical and bioactive compounds of apple and pineapple juices. 
Materials and Methods

\section{Sample preparation}

\section{Apple juice}

Fresh apples of approximately same size were purchased from local market at IIT Kharagpur. Surface of apples was properly cleaned with distilled water followed by $1 \%$ sodium hypochlorite sanitize solution (Walter et al., 2009). Since sodium hypochlorite is harmful for health, hence the apples again properly cleaned with distilled water. After cleaning apples, seeds were removed and pulp portion was sliced and separated. The pulp was then mixed thoroughly to remove any lumps. Cut pieces were put in fruit juicer (maximum RPM: 6000) for 5 minutes and homogenized in dispenser (3000 RPM) for 45 minutes. This was queezed for apple juice using a filter paper. The samples were then immediately stored and frozen at $-25^{\circ} \mathrm{C}$ and were thawed to room temperature before treatment.

\section{Pineapple juice}

Whole Pineapples were procured from local market at IIT Kharagpur. Pineapples were washed with distilled water followed by $\mathrm{NaOCl}$ solution (5 ppm). Skin, eyes, core was removed and cut into small pieces. The small pieces were put in fruit Juicer (maximum RPM: 6000) for 5 minutes, and homogenize in dispenser (3000 RPM) for 4-5 minutes. This puree was squeezed for clear juice using a filter paper. The samples were then immediately stored and frozen at $-25{ }^{\circ} \mathrm{C}$ and were thawed to room temperature before treatment.

\section{Chemicals and reagents}

All the chemicals and reagents used in the study were analytical grade and procured from Merck, India and Sigma-Aldrich, Germany.

\section{Ultraviolet treatment of apple and} pineapple juices

Apple and pineapple juices were processed using batch type UV-C apparatus designed and fabricated (REF) at IIT Kharagpur. The system was designed such a way that, the distance of sample from lamp source can be varied. An $18 \mathrm{~W}$ low pressure mercury vapor UV lamp which emits the UV-C light continuously in the wave length ranges from 200-300 nm were mounted at the top of treatment chamber. Time of UV-C exposure was controlled using a manually operated control switch.

Measured quantity of apple and pineapple juices were poured in $100 \mathrm{~mm}$ standard size petri plates and placed at the center of holder platform (used for maintain different distances between sample and lamp source). 1 $\mathrm{mm}$ sample thickness was maintained throughout the experiment. To prevent the exposure of UV light to human skin, a cover was placed in front of the system.

\section{Experimental design}

Full factorial design was used in this experiment with two independent variables (viz. treatment time and distance of sample from lamp source) of 3 and levels respectively. Responses such as $\mathrm{pH}$, TSS, Absorbance, Color, Vit-C, Antioxidant activity and Total phenolic content were measured before and after the experiment. Analysis of variance (ANOVA) test was conducted using Design expert version 7.0.0 software (State-Ease Inc., Minneapolis, USA) to evaluate the significance (at 95\% confidence level) of the effect of independent variables and their interactions on the responses. 
Measurement of physicochemical properties of apple and pineapple juices

\section{Determination of $\mathbf{p H}$}

Measurement of $\mathrm{pH}$ values of the samples were carried out by using a bench top $\mathrm{pH}$ meter (make: Toshiba, model: CL-46 Plus) at room temperature.

\section{Determination of TSS (Total soluble solids)}

A handheld Refracto meter was used to determine the brix levels of the juice samples.

A few drops of the sample were put into the reading cell and the results at $20{ }^{\circ} \mathrm{C}$ were recorded.

Determination of absorbance of juice samples

Absorbance values of juice samples were determined using Spectrophotometer (Model: UV-1700 Pharma, Make: Shimadzu, Japan) at $254 \mathrm{~nm}$. Different dilution factors were applied (1:10, 1:25, 1:50, 1:100, 1:250, 1:500 and 1:1000). Absorbance coefficient was estimated from the slope of absorbance versus sample concentration plot.

\section{Color measurements of juice samples}

Color parameters of juice samples were detected employing a portable colorimeter (Make: BYK Gardener, Germany; Model: Spectro-guide 45/0gloss). CIE tristimulus L* (brightness-darkness), a* (redness-greenness), and $b^{*}$ (yellowness-blueness) values were obtained before and after the UV exposure. Also total color difference $(\Delta \mathrm{E})$ was calculated according to the following formula (1).

$\Delta E^{*}=\sqrt{\left(L_{0}^{*}-L_{1}^{*}\right)^{2}+\left(a_{0}^{*}-a_{1}^{*}\right)^{2}+\left(b_{0}^{*}-b_{1}^{*}\right)^{2}}$
Measurement of bioactive components of apple and pineapple juices

\section{Measurement of vitamin- $C$ content}

Vitamin $-\mathrm{C}$ content was measured by 2 , 6dichlorophenolindophenol method. A blue substance called $2, \quad 6-$ dichlorophenolindophenol (or DCPIP for short) acts as an indicator. It changes from blue to red with acids but loses its colour in the presence of certain chemicals, one of which is ascorbic acid (vitamin C). DCPIP solution was used to estimate the amount of vitamin $\mathrm{C}$ in foods.

A sample of $105 \mathrm{mg}$ of $\mathrm{Na}_{2} \mathrm{CO}_{3}$ was mixed with $500 \mathrm{ml}$ of hot glass distilled water using a magnetic stirrer. $125 \mathrm{mg}$ of DCPIP was mixed with this solution and stirring was done until the solution came to room temperature. Dye solution was then filtered and stored at 4 ${ }^{\circ} \mathrm{C}$. Also, Dye factor was found by titration.

A 500ml solution of $\mathrm{HPO}_{3}$ was prepared and this was used for dilutions of ascorbic acid solution. A $100 \mathrm{ml}$ solution of ascorbic acid $(100 \mathrm{mg} / 100 \mathrm{ml})$ was prepared and was diluted 10 times using $\mathrm{HPO}_{3}$ solution. This was used as the working solution. $2 \mathrm{ml}$ of juice sample was mixed with $18 \mathrm{ml}$ of $\mathrm{HPO}_{3}$ and was titrated against the dye solution.

\section{Measurement of anti-oxidant capacity}

The phenolic compounds present in sample were solubilized in $80 \% \mathrm{v} / \mathrm{v}$ ethanol made in ultra-pure water. A five gram sample was mixed with $20 \mathrm{~mL}$ of solvent and kept in a shaker for $3 \mathrm{~h}$ at $25^{\circ} \mathrm{C}$.

The supernatant obtained after centrifugation at $12,000 \mathrm{rpm}$ at $4{ }^{\circ} \mathrm{C}$ was considered as the extract for measuring both total phenolic content (TPC) and antioxidant capacity. 
A DPPH solution was made using approximately $15 \mathrm{mg}$ DPPH in $100 \mathrm{ml}$ methanol. Its absorbance at $517 \mathrm{~nm}$ was adjusted to unity and it was kept in the dark at $-20^{\circ} \mathrm{C}$ till further use. The change in color of the DPPH solution from purple to yellow, resulting from the addition of different quantities of ethanolic extract of juices or gallic acid (GA) standard (20 to $200 \mu \mathrm{l})$ was measured at $517 \mathrm{~nm}$ after allowing the solution to stand in the dark for $20 \mathrm{~min}$. The decrease in absorbance of DPPH after 20 min was calculated and expressed as mg of GA equivalents antioxidant capacity (GAEAC) per $100 \mathrm{~g}$.

\section{Measurement of Total phenolic content (TPC)}

TPC in the sample extract was determined by the Folin-Ciocalteu method. Equal volume of the sample extract and Folin-Ciocalteu reagent (FCR) $(0.25 \mathrm{~mL}$ each) was mixed with $750 \mu \mathrm{L}$ of $20 \%$ sodium carbonate solution and it was diluted to $5 \mathrm{~mL}$ by double distilled water followed by a vortex. After incubation at $25^{\circ} \mathrm{C}$ in the dark for $1.5 \mathrm{~h}$, the absorbance of blue color was measured at $750 \mathrm{~nm}$ in a UV-VIS spectrophotometer (Model: UV-1700 Pharma Spec, Make: Shimadzu, Japan). The comparison was made with a calibrated curve made of different gallic acid (Sigma-Aldrich, Germany) concentrations and TPC values were expressed as gallic acid equivalent (GAE) per $100 \mathrm{~g}$ sample.

\section{Results and Discussion}

\section{Physicochemical and bioactive components of raw samples}

The physicochemical properties of raw apple and pineapple juices were measured with three replications and the results were presented in table 1 . From obtained results, we can be observed that the $\mathrm{pH}$ values for apple juice is not very low indicating that the juice is less acidic compared to pineapple juice. The absorbance values indicate that the penetration of UV-light in apple juice is higher than that in pineapple juice. The Vitamin-C contents indicate that it is of significance in pineapple juice while it is not of much importance in apple juice.

\section{Effect of UV-C treatment on pH}

The $\mathrm{pH}$ of the samples after treatments at different dosage levels is represented in the table 2. It can be inferred from the results that there is no impact on the $\mathrm{pH}$ levels of both apple juice and pineapple juice for any of the treatments.

\section{Effect of UV-C treatment on TSS}

The TSS of the samples after treatments at different dosage levels is represented in the table 3. It can be inferred from the results that there is no impact on the TSS levels of both apple juice and pineapple juice for any of the treatments.

\section{Effect of UV-C treatment on color}

Effect of UV-C on color components of apple is presented in fig.1, 2, and 3. The obtained results showed that, there is no significant effect of UV-C treatment on $\mathrm{a}^{*}$ values of apple. However, there is significant decrease in $\mathrm{L}^{*}, \mathrm{~b}^{*}$ values with increasing in UV dosage. Further, the total color difference of pineapple juice during $\mathrm{UV}-\mathrm{C}$ treatment is presented in figure 4 . From the results we can observed that, there is very little colour deviation $\left(<2.5 \Delta \mathrm{E}^{*}\right)$ in any of the treatments. However at higher dosages the colour has changed considerably compared to the lower dosages. This can be observed from the fact that the treatments at the closer distances to the lamp and the higher time of exposure have impacted the colour significantly compared to other treatments. 
Effect of UV-C treatment on the vitamin-C content

The effect of UV treatment on Vitamin-C content of pineapple juices has been represented in the Figure 5. The obtained results showed that, the Vitamin-C content of apple and pineapple juices were significantly affected by treatment conditions. It is inferred that the Vitamin-C content is dependent on the UV-C dosage rather than the distance from lamp source. Vitamin $\mathrm{C}$ is a light sensitive Vitamin degrades in presence of UV light. It is inferred that the Vitamin-C content is dependent on the UV-C dosage rather than the distance from lamp source. There was a reduction of up to $18 \%$ at the higher dosage levels while the lower dosages had minimal or no effect on the Vitamin $\mathrm{C}$ content of the juice. A test runs of 30 minutes exposure at the minimum distance from lamp source $(8.64$ $\mathrm{cm})$ resultedina $40 \%$ reduction of Vitamin-C content. This experimentation was not conducted for apple juice as it was found that the Vit-C content of the apples juice made was insignificant $(1 \mathrm{mg} / 100 \mathrm{ml})$.

\section{Effect of UV-C treatment on the anti-} oxidant capacity

The impact on antioxidant activity at various levels of treatment for apple and pineapple juice is represented in Fig. 6 and Fig. 7, respectively. The antioxidant activity of UV treated apple juice was lower than the control sample but with no significant difference. A decreasing trend was observed with increasing dosage levels. At the highest dosage applied there was a decrease of only $8 \%$ in AAC in apple juice. The reason for this decrease in AAC could be the light sensitive anti-oxidant components like ascorbic acid, carotenoids, phenols etc present in the pineapple juice which can easily undergo photolysis in the presence of UV light. The same decreasing trend was observed in pineapple juice.

Table.1 Physico chemical properties of control samples

\begin{tabular}{|c|c|c|}
\hline Property & Apple & Pineapple \\
\hline $\mathrm{pH}$ & $4.28 \pm 0.02 @ 26.7{ }^{0} \mathrm{C}$ & $3.46 \pm 0.02 @ 26{ }^{0} \mathrm{C}$ \\
\hline TSS & $14.3 \pm 0.01^{\circ} \mathrm{Brix}$ & $11.3 \pm 0.1{ }^{0}$ Brix @ $26{ }^{0} \mathrm{C}$ \\
\hline Color & $\begin{array}{l}\mathrm{L}^{*}=17.82 \mathrm{a}^{*}=6.41 \\
\mathrm{~b}^{*}=16.64\end{array}$ & $\begin{array}{l}L^{*}=30.48 a^{*}=-1.41 \\
b^{*}=16.00\end{array}$ \\
\hline Titrable Acidity & $0.42 \pm 0.04$ & $0.58 \pm 0.04$ \\
\hline $\begin{array}{l}\text { Total Phenolic } \\
\text { Content } \\
(\mathrm{mg} \text { GAE/100 } \\
\mathrm{ml})\end{array}$ & $48.68 \pm 2.1$ & $29.6 \pm 1.7$ \\
\hline $\begin{array}{l}\text { Antioxidant } \\
\text { Activity } \\
(\mathrm{mg} \quad \mathrm{GAE} / 100 \\
\mathrm{ml})\end{array}$ & $21.3 \pm 0.8$ & $14.6 \pm 1.1$ \\
\hline $\begin{array}{ll}\text { Vitamin } & C \\
(\mathrm{mg} / 100 \mathrm{ml}) & \end{array}$ & $1.5 \mathrm{mg} / 100 \mathrm{ml}$ & $16.9 \mathrm{mg} / 100 \mathrm{ml}$ \\
\hline
\end{tabular}


Table.2 Effect on $\mathrm{pH}$ on application UV Dosage at various levels of treatments

\begin{tabular}{|c|c|c|c|}
\hline $\begin{array}{l}\text { Distance } \\
(\mathbf{c m})\end{array}$ & $\begin{array}{l}\text { Exposure time } \\
(\mathrm{min})\end{array}$ & Apple Juice pH & Pineapple juice $\mathbf{p H}$ \\
\hline 8.6 & 5 & $4.32 \pm 0.01$ & $3.44 \pm 0.01$ \\
\hline 8.6 & 10 & $4.32 \pm 0.01$ & $3.45 \pm 0.01$ \\
\hline 8.6 & 15 & $4.32 \pm 0.01$ & $3.44 \pm 0.01$ \\
\hline 13.7 & 5 & $4.29 \pm 0.01$ & $3.42 \pm 0.01$ \\
\hline 13.7 & 10 & $4.29 \pm 0.01$ & $3.43+/-0.01$ \\
\hline 13.7 & 15 & $4.29 \pm 0.01$ & $3.45 \pm 0.01$ \\
\hline 18.6 & 5 & $4.29 \pm 0.01$ & $3.43 \pm 0.01$ \\
\hline 18.6 & 10 & $4.30 \pm 0.01$ & $3.43 \pm 0.01$ \\
\hline 18.6 & 15 & 4. $30 \pm 0.01$ & $3.43 \pm 0.01$ \\
\hline 22.8 & 5 & $4.30 \pm 0.01$ & $3.43 \pm-0.01$ \\
\hline 22.8 & 10 & $4.29 \pm 0.01$ & $3.44 \pm 0.01$ \\
\hline 22.8 & 15 & $4.29 \pm 0.01$ & $3.43 \pm 0.01$ \\
\hline
\end{tabular}

Values are presented as mean \pm standard deviation $(n=4)$

Table.3 Effect of TSS over application of UV Dosage at various treatment conditions

\begin{tabular}{llll}
\hline $\begin{array}{l}\text { Distance } \\
(\mathbf{c m})\end{array}$ & $\begin{array}{l}\text { Exposure time } \\
(\mathbf{m i n})\end{array}$ & Apple Juice TSS $\left({ }^{\mathbf{0}} \mathbf{B r i x}\right)$ & $\begin{array}{l}\text { Pineapple juice TSS } \\
\left({ }^{\mathbf{0}} \mathbf{B r i x}\right)\end{array}$ \\
\hline 8.6 & 5 & $14.3 \pm 0.01$ & $11.3 \pm 0.1$ \\
8.6 & 10 & $14.3 \pm 0.01$ & $11.2 \pm 0.1$ \\
8.6 & 15 & $14.5 \pm 0.01$ & $11.5 \pm 0.1$ \\
13.7 & 5 & $14.3 \pm 0.01$ & $11.3 \pm 0.1$ \\
13.7 & 10 & $14.3 \pm 0.01$ & $11.4 \pm 0.1$ \\
13.7 & 15 & $14.4 \pm 0.01$ & $11.4 \pm 0.1$ \\
18.6 & 5 & $14.3 \pm 0.01$ & $11.3 \pm 0.1$ \\
18.6 & 10 & $14.3 \pm 0.01$ & $11.3 \pm 0.1$ \\
18.6 & 15 & $14.4 \pm 0.01$ & $11.4 \pm 0.1$ \\
22.8 & 5 & $14.3 \pm 0.01$ & $11.3 \pm 0.1$ \\
22.8 & 10 & $14.3 \pm 0.01$ & $11.3 \pm 0.1$ \\
22.8 & 15 & $14.4 \pm 0.01$ & $11.4 \pm 0.1$ \\
\hline
\end{tabular}

Values are presented as mean \pm standard deviation $(\mathrm{n}=4)$ 
Fig.1 Effect of UV-C radiation on $\mathrm{L}^{*}$ values of apple juice

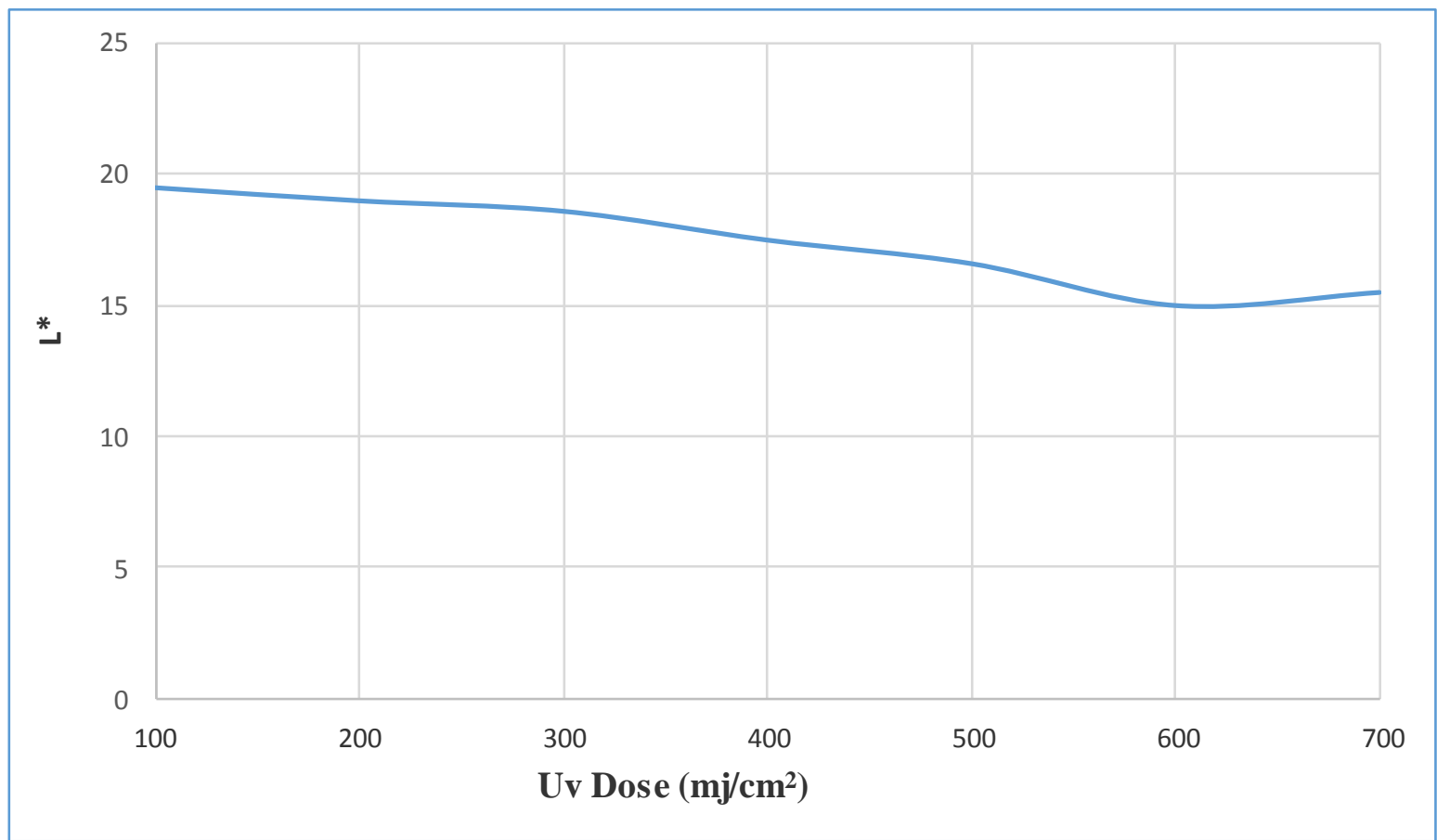

Fig.2 Effect of UV-C radiation on $a^{*}$ values of apple juice

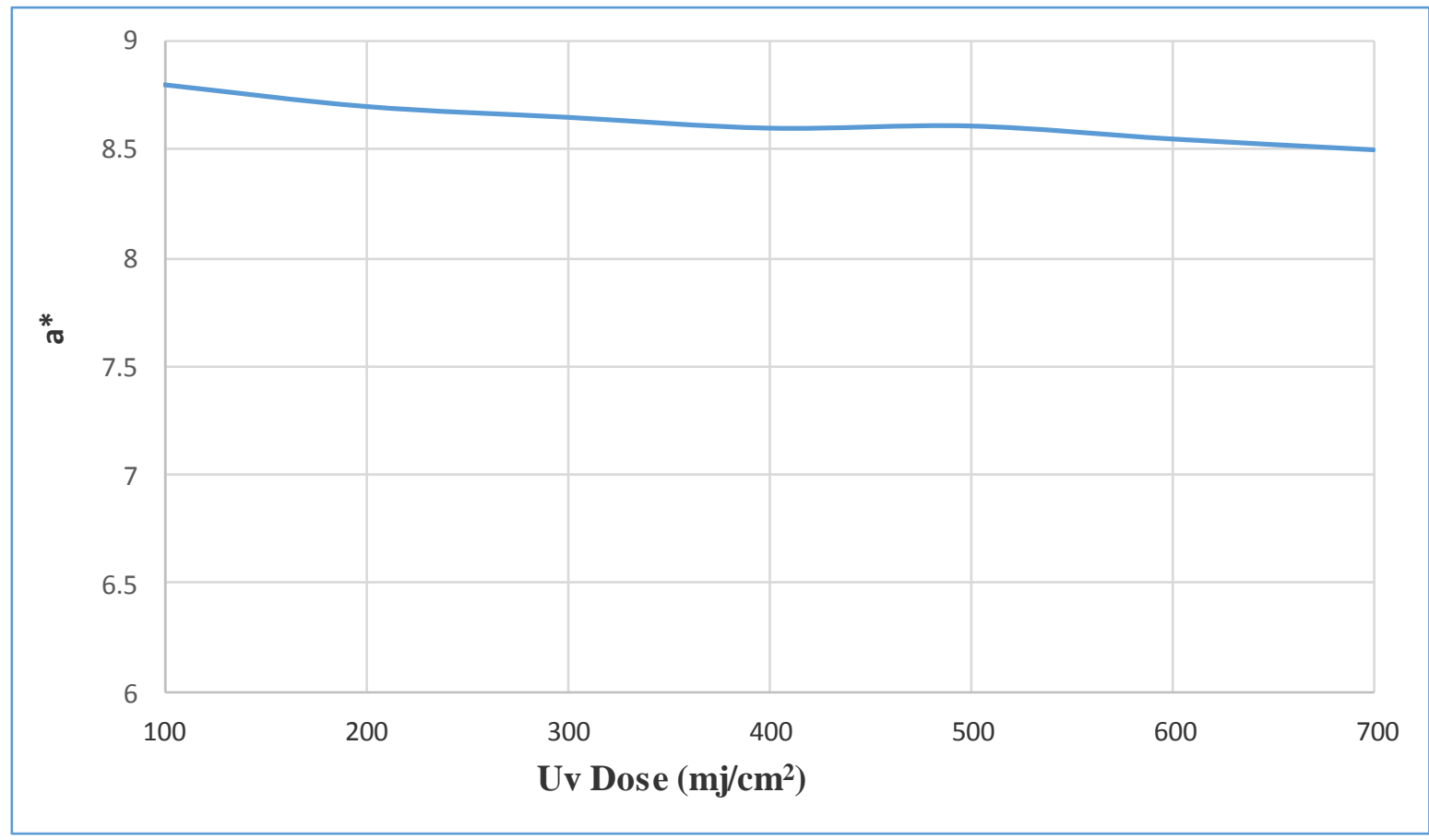


Fig.3 Effect of UV-C radiation on $b^{*}$ values of apple juice

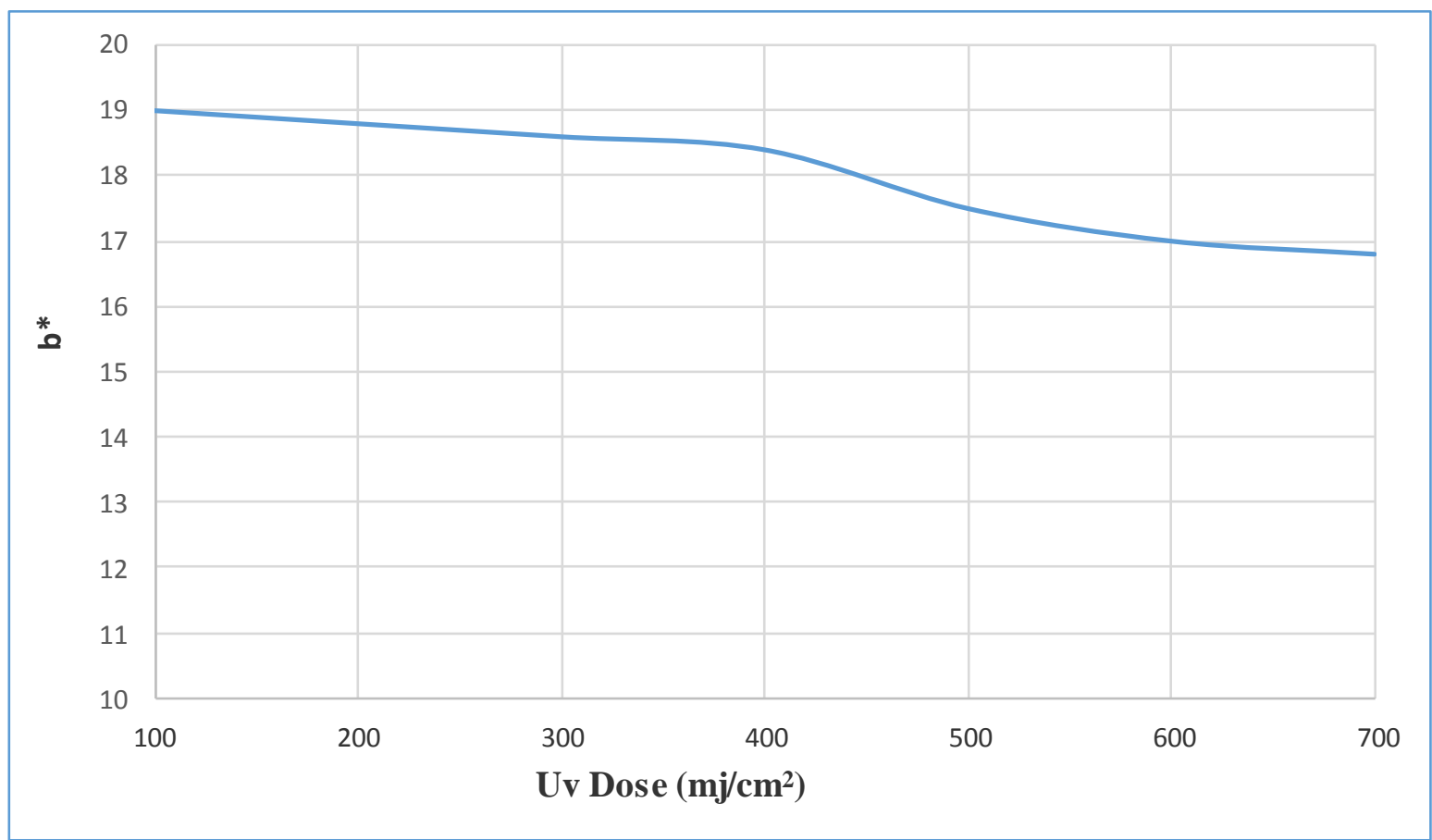

Fig.4 Impact of UV Dosage on colour of Pineapple juice

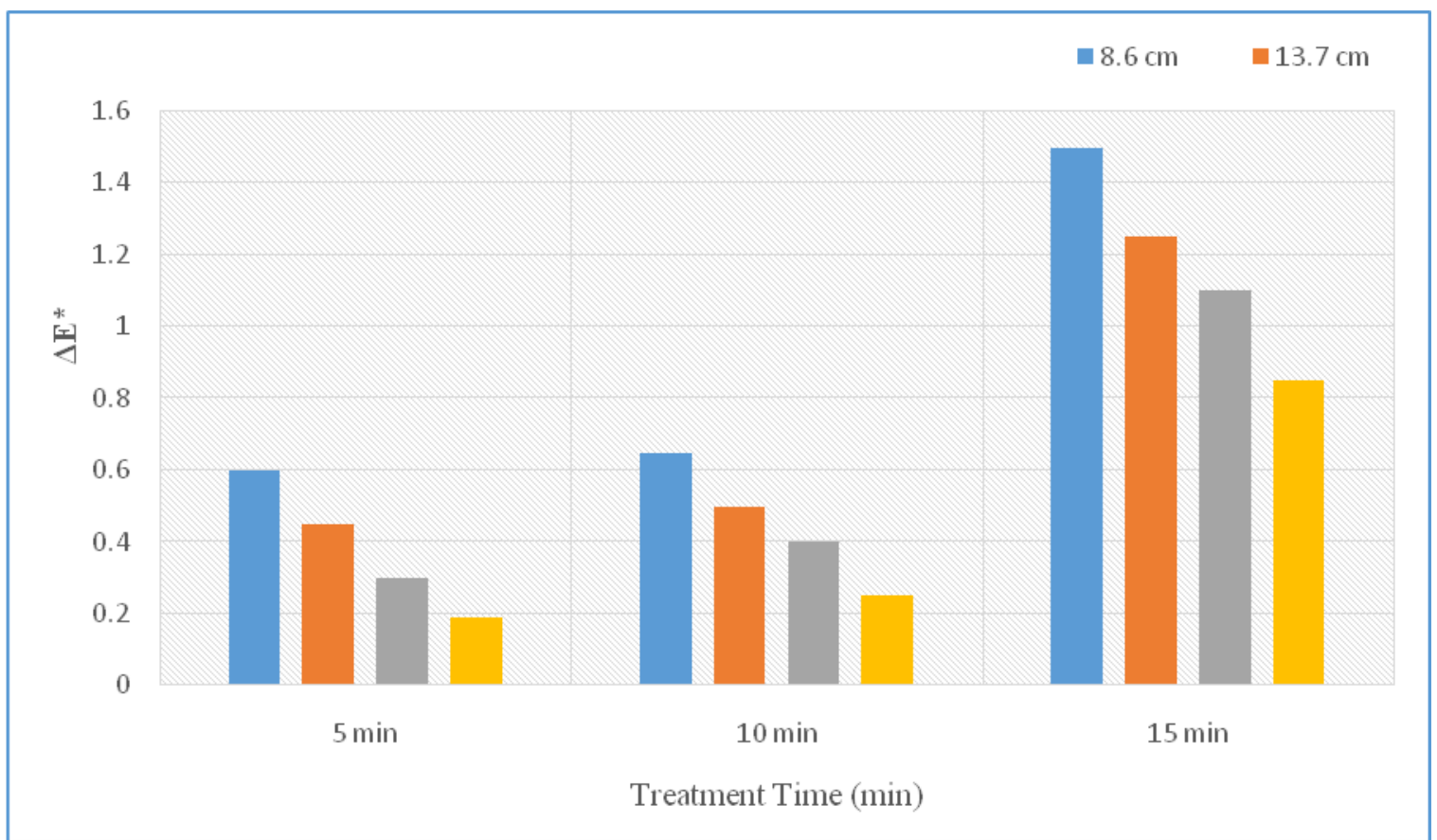


Fig.5 Impact of UV Dosage on the Vitamin-C content of pineapple juice

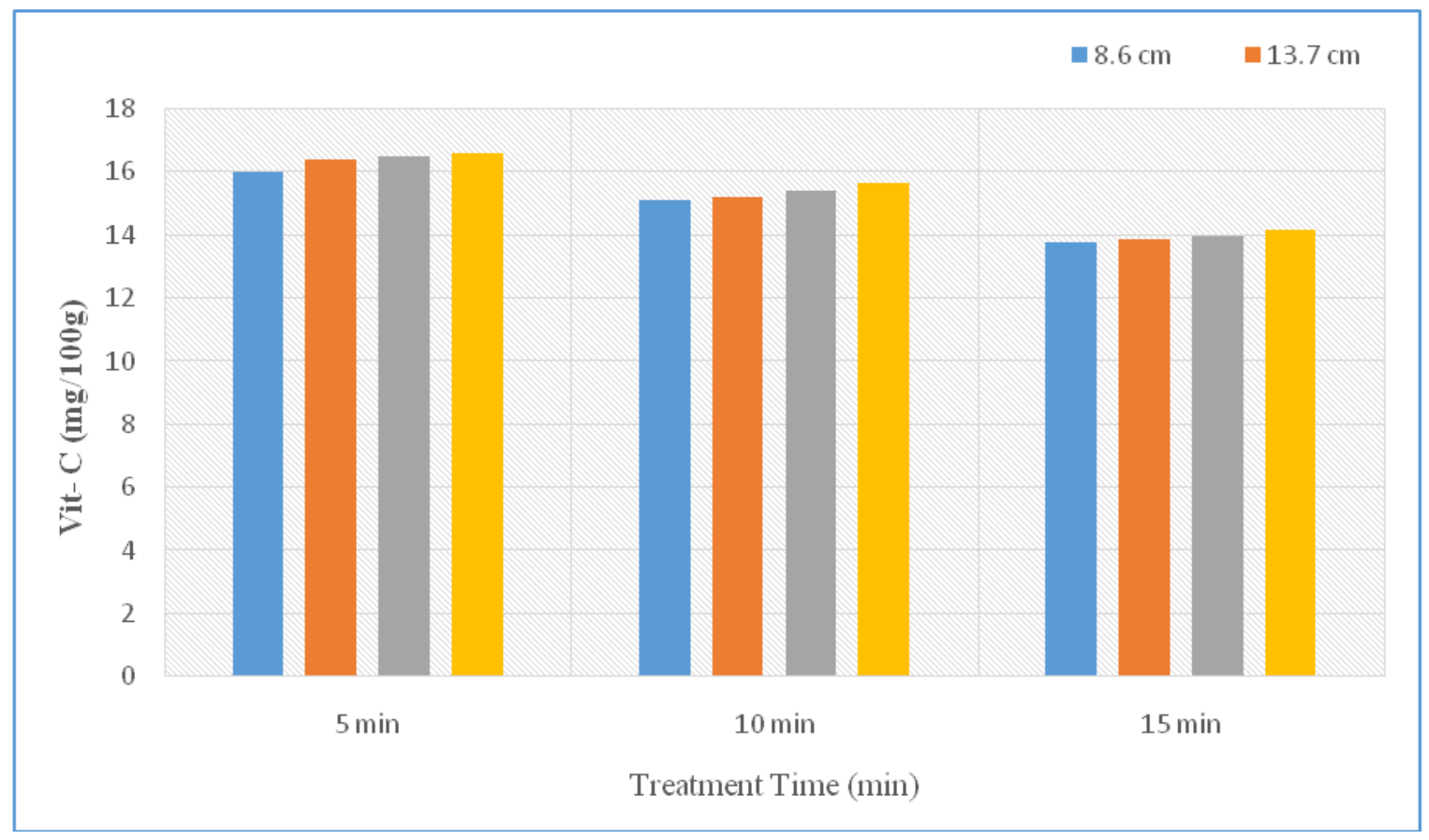

Fig.6 Impact of UV treatment on AAC of apple juice

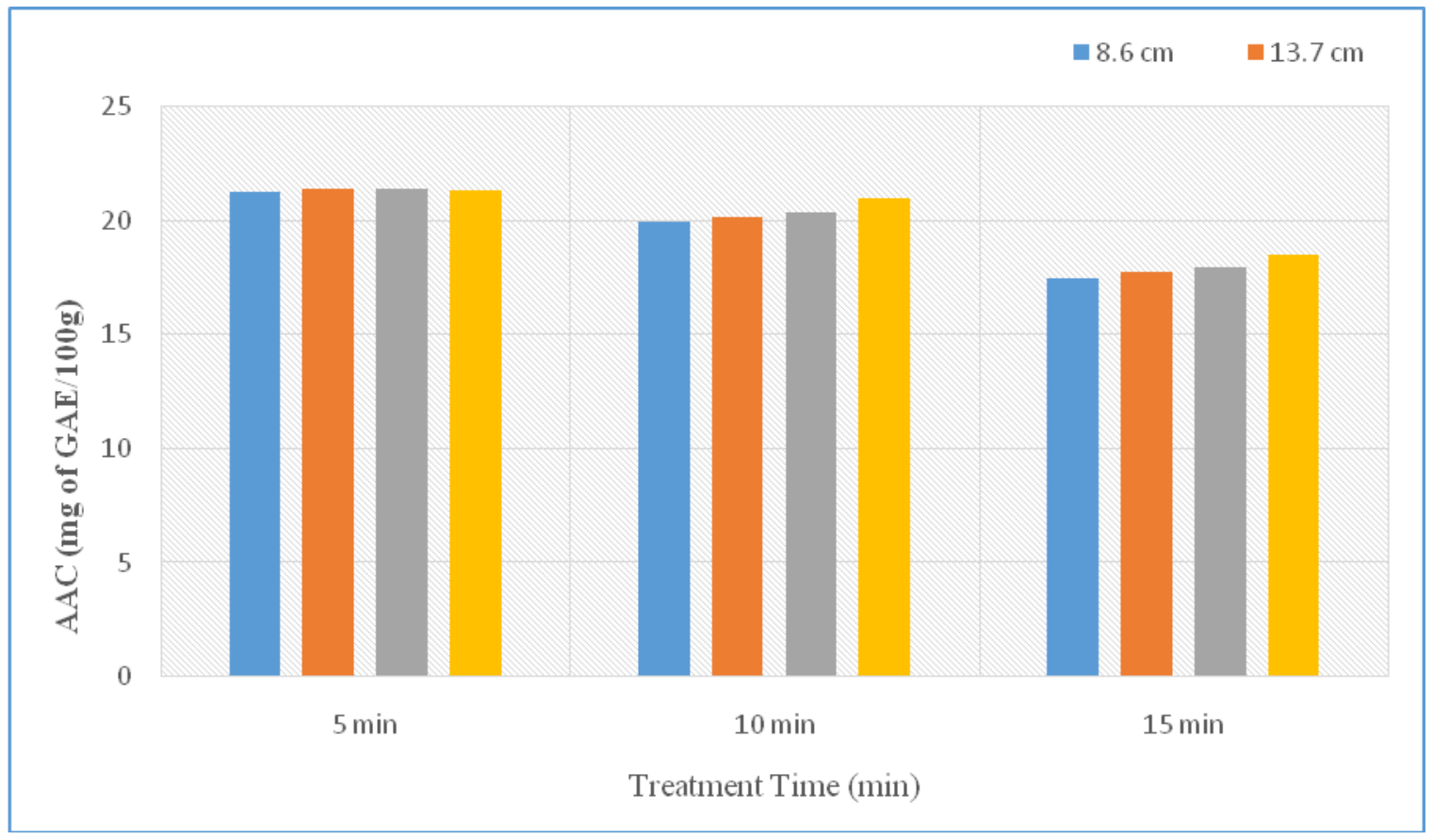


Fig.7 Impact of UV treatment on AAC of pineapple juice

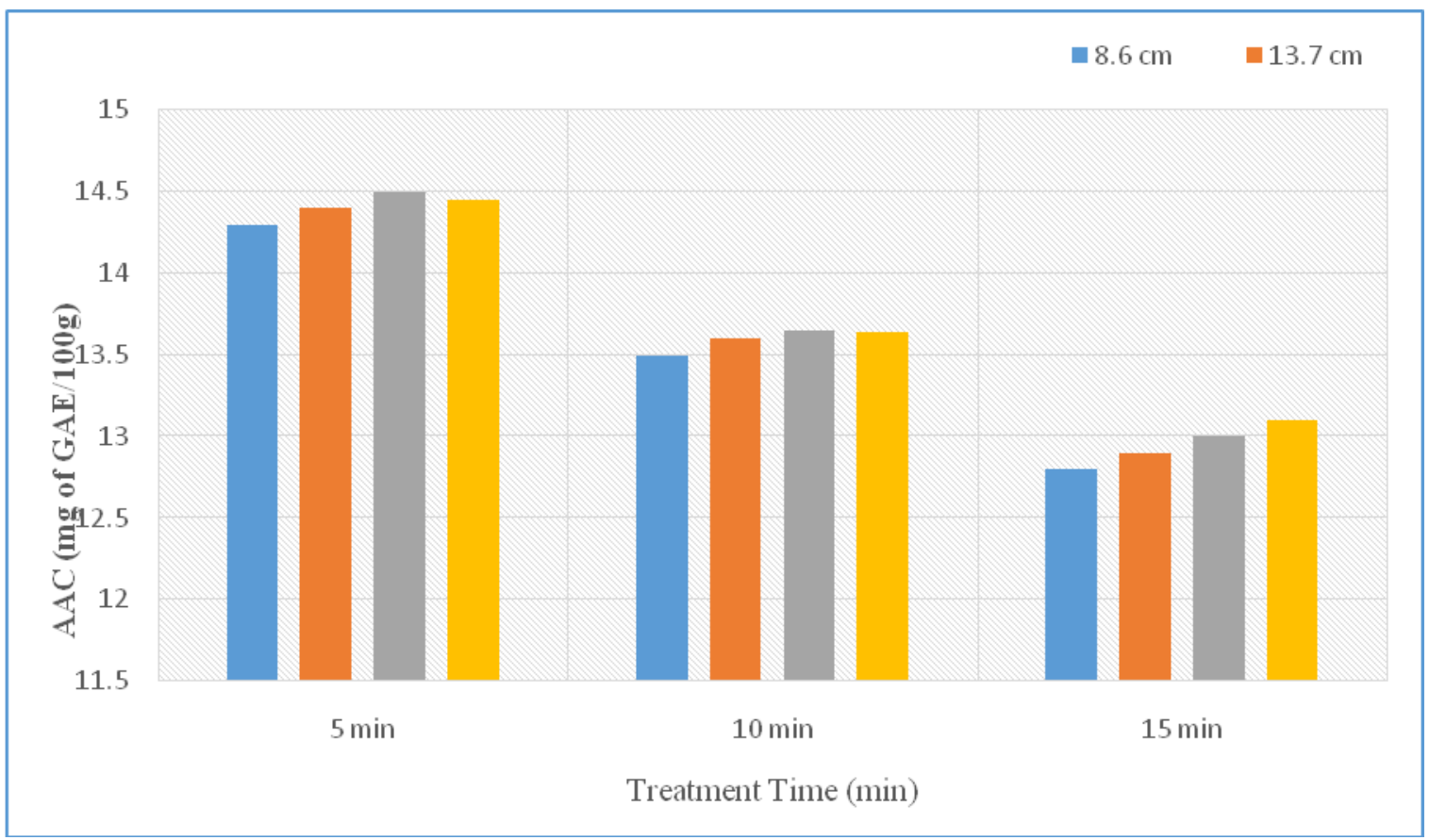

Fig.8 Impact of UV treatment on TPC of pineapple juice

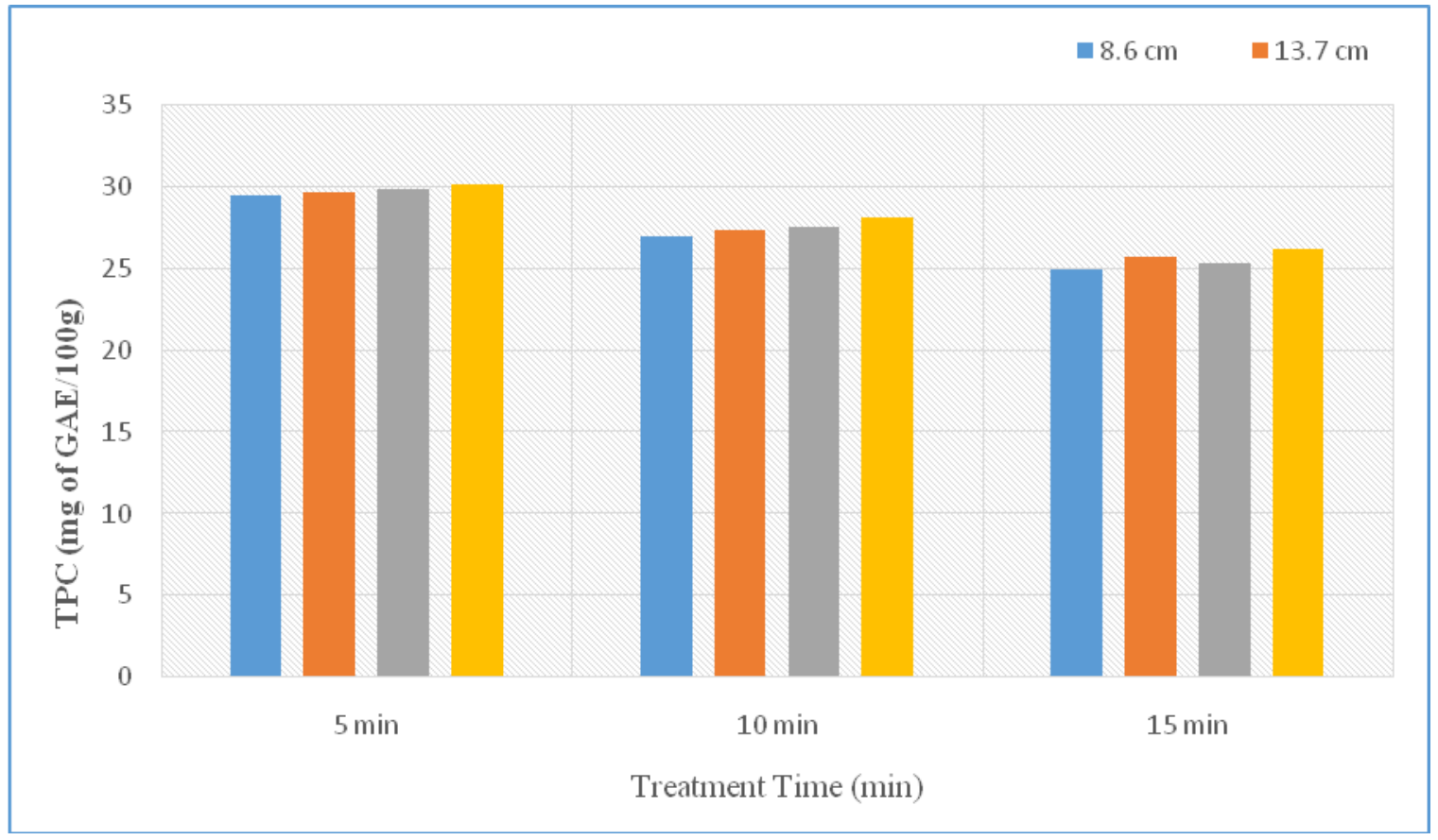




\section{Effect of UV-C treatment on the total phenolic content}

The effect of treatment conditions on TPC on pineapple juice has been represented in the Fig 8.

The total phenolic content of UV treated samples have shown an overall decreasing trend with increasing UV dosage but not significant as compared to the control sample. At the highest dosage applied there was a decrease of only $8 \%$ in TPC.

Effect of UV-C treatment on apple and pineapple juices was studied during this research work. The results obtained from this study showed that the ultraviolet treatment (UV) doesn't have any significant effect on $\mathrm{pH}$, TSS of apple and pineapple juices. However, the UV treatment conditions had significant effect on vitamin-C content. The color parameters (viz. $L^{*}, a^{*}$ and $b^{*}$ ) were slightly affected by ultraviolet treatment. The bioactive components of apple and pineapple juices were affected by the treatment conditions.

The Antioxidant activity of both the juices showed a decreasing trend with respect to an increase in dosage level. The obtained results suggested that, ultraviolet treatment conditions slightly affect the quality parameters of apple and pineapple juices. However, the changes were found to be minimum as that of thermal treatments in literature. Hence we can conclude that, the UV-C treatment is effective method to processing apple and pineapple juices.

\section{Acknowledgment}

The authors express sincere thanks to IIT Kharagpur and ministry of MHRD, Govt. of India for providing financial support during the tenure of research work.

\section{References}

Anderson, J. G., Rowan, N. J., MacGregor, S. J., Fouracre, R. A. and Farish, O. (2000). Inactivation of food-borne enteropathogenic bacteria and spoilage fungi using pulsed-light. Plasma Science, IEEE Transactions on Plasma Science, 28(1), 83-88.

Bates, R. P., Morris, J. R. and Crandall,P. G.(2001). Principles and practices of small-and medium-scalefruit juice processing. FAO Agricultural Services Bulletin, 146,135-149.

Begum, M., Hocking, A.D. and Miskelly, D. (2009). Inactivation of food spoilage fungi by ultraviolet (UVC) irradiation. International Journal Food Microbiology, 129, 74-77.

Bintsis, T., Tzanetaki, E.L. and Robinson, R.K., (2000). Existing and potential applications of ultraviolet light in the food industry - a critical review. Journal of the Science of Food and Agriculture, 80, 637-645.

Bolton, J.R. Ultraviolet Applications Handbook, 1st Ed. 1999, Ayr, Ontario, Canada, Bolton Photosciences, Inc.

Bolton, J. R., Linden, K. G., and Asce, M. (2003). Standardization of method for fluence UV dose determination in benchscale UV experiments. Journal of EnvironmentalEngineering,129(3), 209215.

Canitez N., 2002. Pasteurization of Apple Cider with UV Irradiation. MS Thesis. The University of Maine.

Caron, E., Chevrefils, Jr.G., Barbeau, B., Payment, P. and Prevost, M., 2007. Impact of microparticles on UV disinfection of indigenous aerobic spores. Water Research 41, 4546-4556.

Chang, S.S. and Kang, D.H., 2004. Alicyclobacillus spp. in the fruit juice industry: history characteristics, and current isolation / detection procedures. Critical Reviews in Microbiology, 30, 55-74. 
Daoudi, L., Quevedo, J.M., Trujillo, J., Capdevila, F., Bartra, E., Mínguez, S. and Guamis, B., 2002. Effects of highpressure treatment on the sensory quality of white grape juice. High Pressure Research. 22,705-709.

Dock, L.L., 1999. Development of thermal and non-thermal preservation methods for producing microbially safe apple cider. Ph.D. Thesis. Purdue University, West Lafayette, IN, USA.

Guerero-Beltran, J. A., andBarbosa-Canovas, G. V. (2005). Reduction of Saccharomyces cerevisiae, Escherichia coli and Listeria innocuain apple juice by ultraviolet light. Journal of Food Process Engineering,28, 437-452.

Pan, J., Vicente, A.R., Martínez, G.A., Chaves, A.R., and Civello, P.M. (2004). Combined use of UV-C irradiation and heat treatment to improve postharvest life of strawberry fruit. Journal of the Science of Food and Agriculture, 84, 1831-1838.

Koutchma, T., Keller, S., Chirtel, S., and Parisi, B. (2004). Ultraviolet disinfection of juice products in laminar and turbulent flow reactors. Innovative Food Science and Emerging Technologies, 5(2), 179189.

Koutchma, T., Parisi, B., and Unluturk, S. K. (2006). Evaluation of UV dose in flowthrough reactors for fresh apple juice and cider. Chemical Engineering Communications, 193(6), 715-728.

Koutchma, T., Parisi, B., and Patazca, E. (2007). Validation of UV coiled tube reactor for fresh juices. Journal of
Environmental Engineering and Science, 6(3), 319-328.

Koutchma,T. (2009). Advances in ultraviolet light technology for non-thermal processing of liquid foods. Food and Bioprocess Technology, 2(2), 138-155.

Kozempel, M., McAloon, A., and Yee, W. (1998). The cost of pasteurizing apple cider. Food Technology, 52(1), 50-52.

Miller, R.V., Jeffrey, W., Mitchell, D. and Elasri, M., 1999. Bacterial responses to ultraviolet light, American Society of Microbiology News 65(8), 535-541.

Min, S., Jin, Z.T., Min, S.K., Yeom, H. and Zhang, Q.H., 2003. Commercial-Scale pulsed electric field processing of orange juice. Journal of Food Science: Food Chemistry and Toxicology, 68(4):12651271.

Opstal, I.V., Bagamboula, C.F., Theys, T., Vanmuysen, S.C.M. and Michiels, C.W., 2006. Inactivation of Escherichia coli and Shigella in acidic fruit and vegetable juices by peroxidase systems. Journal of Applied Microbiology, 101, 242-250.

Tandon, K., Worobo, R. W., Churey, J. J., and Padilla-Zakour, O. I. (2003). Storage quality of pasteurized and UV treated apple cider. Journal of Food Processing, 27(1), 21-35.

Tran, M.T.T. and Farid, M., 2004. Ultraviolet treatment of orange juice. Innovative Food Science and Emerging Technologies 5,495-502.

Wang, T., Macgregor, S.J., Anderson, J.G. and Woolsey, G.A., 2005. Pulsed ultra-violet inactivation spectrum of Escherichia coli. Water Research 39, 2921-292.

\section{How to cite this article:}

Krishna Teja, C., Shivashankar Sanganamoni, B. Prabhakar and Pavuluri Srinivasa Rao. 2017. Effect of UV-C Light Treatment on Physicochemical and Bioactive Compounds in Apple and Pineapple Juices. Int.J.Curr.Microbiol.App.Sci. 6(6): 2321-2333. doi: https://doi.org/10.20546/ijcmas.2017.606.275 